\title{
A TERRITORIALIDADE SERINGUEIRA Geografia e Movimento Social
}

\author{
Carlos Walter Porto Gonçalves \\ Universidade Federal Fluminense
}

\section{Introdução}

Neste artigo objetivamos avançar algumas reflexões, em grande parte generalizações, a respeito do Movimento Social como categoria geográfica, partindo do rico material empírico obtido da minha experiência como assessor do Conselho Nacional dos Seringueiros (1987 e 1992) e da pesquisa que culminou em minha tese de Doutorado (1993 e 1998). Seu tema é, portanto, Movimento Social e Organização do Espaço.

O movimento dos seringueiros acreanos é, a esse respeito, emblemático, pela importância que emprestou à sociedade/geografia acreana como resultado da interseção de múltiplos processos instituintes que ali se territorializaram.

O melhor exemplo disso é o fato de o Acre, em 1998, ter dois dos três Senadores da República ligados a um movimento social em grande parte tecido em torno das lutas dos seringueiros; quatro dos doze Prefeitos Municipais do Estado ligados ao mesmo processo instituinte; o Governador do Estado eleito pelo mesmo partido a que estavam ligadas as principais lideranças do movimento dos seringueiros que, diga-se de passagem, teve no Acre o primeiro Estado da federação em que o Partido dos Trabalhadores foi legalizado ${ }^{1}$; a Comissão Pastoral da Terra teve seu primeiro coordenador nacional o Bispo da Prelazia do Acre-Purus, D. Moacir Grechi, exatamente a região onde se travaram as intensas lutas dos seringueiros. Resta saber se toda essa arquitetura política, principal conquista da sociedade civil acreana que teve, sem dúvida, o movimento dos seringueiros como seu eixo estruturante, será capaz de consolidar os elos políticos que os levou até aí e, nas novas circunstâncias, propiciar instituições que não substituam os sujeitos

1 - Ao qual estavam ligadas as principais lideranças seringueiras. 
instituintes. Afinal, a justiça social e a participação democrática autogestionária sempre foram as principais reivindicações deste movimento.

\section{Considerações Teóricas}

A configuração de qualquer identidade político-cultural é parte constitutiva dos grupos/segmentos sociais que se põem em movimento. $\mathrm{O}$ historiador marxista inglês E. Thompson já nos alertara que a classe social 'é uma relação e não uma coisa' (THOMPSON, 1987 : 11) e, assim, abria espaço para questionar o sentido extremamente arraigado de na expressão luta de classes enfatizar-se o lado classes e secundarizar o lado luta ${ }^{2}$. Assim desemboca-se, com facilidade, naquilo que, em outro contexto, Pierre Bourdieu (1989) chamara de 'classes no papel'. Confundese, com frequiência, o modo como os grupos/segmentos/classes sociais se constituem nas e pelas circunstâncias das relações com que concretamente têm que se haver, de um lado, com o processo de conhecimento, de outro.

Qualquer classificação significa, rigorosamente, estabelecer um sistema de classes. Trata-se de um processo heurístico que permite ao analista estabelecer parâmetros importantes para desvendar aspectos relevantes da realidade que se propõe estudar. Classificar significa reunir segundo determinados critérios e, assim, discriminar, separar. Organiza-se assim um mapa 'lógico' onde uma dada realidade é enquadrada para análise. Envolvido nesse universo gnoseológico o pesquisador deve tomar todo o cuidado para não confundir as coisas da lógica com a lógica das coisas. Pressupõe-se, por exemplo, que os lugares estão dados a priori e não que os lugares sejam, eles mesmos, instituídos ${ }^{3}$. A materialidade do espaço geográfico, sem dúvida, propõe/impõe/põe condições às mudanças de lugar. "Qualquer ação que tenha em vista opor o provável ao possível, isto é, ao porvir objetivamente inscrito na ordem estabelecida tem de contar com o peso da história reificada e incorporada que, como um processo de envelhecimento, tende a reduzir o possível ao provável" (BOURDIEU, 1989 : 101).

Pierre Bourdieu, com sua preocupação com o espaço social, abre uma importante senda para um diálogo com a geografia, particularmente com a concepção teórica que abraçamos, que entende a geografia menos como um substantivo e mais como um verbo, ou melhor, como o ato/a ação de marcar a terra, de geografar. Nessa perspectiva teórica, as marcas, os limites, as fronteiras são sempre instituídas e, como tais, implicam sujeitos instituintes o que nos remete à própria configuração do que seja a sociedade como tal. É Bourdieu quem nos diz que

Num primeiro momento a sociologia apresenta-se como uma topologia social. Pode-se representar o mundo social em forma de um espaço (a várias dimensões) construído na base de

\footnotetext{
2 - Ver, também, do mesmo autor 'A Miséria da Teoria' (THOMPSON, 1981)

3 - E aqui é que as observações do também marxista E. Thompson, do sociólogo Pierre Bourdieu, dos filósofos Cornelius Castoriadis e Henri Lefebvre ganham relevância ao lado dos geógrafos E. Soja, D. Harvey, Milton Santos, Marcelo J. L. de Souza, Regina Sader e outros.
} 
princípios de diferenciação ou de distribuição constituídos pelo conjunto das propriedades que actuam no universo social considerado, quer dizer, apropriadas a conferir, ao detentor delas, força ou poder neste universo. Os agentes e grupos de agentes são assim definidos pelas suas posições relativas neste espaço. Cada um deles está acantonado numa posição ou numa classe precisa de posições vizinhas, quer dizer, numa região determinada do espaço, e não se pode ocupar realmente duas regiões opostas do espaço - mesmo que tal seja concebível. Na medida em que as propriedades tidas em consideração para se construir este espaço são propriedades actuantes, ele pode ser descrito como um campo de forças, quer dizer, como um conjunto de relações de forças objetivas impostas a todos os que entrem nesse espaço e irredutíveis às intenções dos agentes individuais ou mesmo às interações diretas entre os agentes'

(BOURDIEU, 1989 : 133-4).

As classes sociais se constituem, assim, nas e pelas lutas que os protagonistas travam em situações concretas e que conformam os lugares que não só ocupam, mas constituem. Relembremos que protagonista deriva do grego protos, primeiro, principal e agonistes, lutador, competidor (CUNHA, 1992: 641). É claro que ao se privilegiar a dimensão luta e não a classe, se abre um enorme espaço à contingência e ao acaso, escapando assim às reduções determinísticas racionalistas.

A expressão movimento social ganha, assim, para a nossa compreensão das identidades coletivas um sentido geográfico muito preciso: é que o vemos como aquele processo através do qual um determinado segmento social recusa o lugar que, numa determinada circunstância espaço-temporal, outros segmentos sociais melhor situados no espaço social pelos capitais (Bourdieu) que já dispõem tentam lhe impor e, rompendo a inércia relativa em que se encontravam, se mobilizam movimentando-se em busca de afirmação das qualidades que acreditam justificarem sua existência. A própria idéia de que toda sociedade institui uma determinada ordem nos remete ao fato de que uma ordem é sempre um determinado modo (ele mesmo instituído) como os entes se colocam entre si configurando uma totalidade que faz sentido para aqueles que a constituíram. Pode-se, por exemplo, falar de ordem alfabética ou de ordem numérica sempre indicando o modo como cada parte se coloca em relação à outra configurando essa mesma ordem. Assim o movimento (social) é, rigorosamente, mudança de lugar (social) sempre indicando que aqueles que se movimentam estão recusando o lugar que lhes estava reservado numa determinada ordem de significações. Deste modo, todo movimento social é portador de uma nova ordem em potencial não sendo destituído de sentido o fato daqueles que se colocam em posição hegemônica numa determinada ordem estigmatizar como desordeiro todo aquele que questiona essa (sua) ordem. Aqui, sem dúvida, geografia e sociologia se tornam imbricadas.

Todavia, insistimos, a passagem de uma determinada condição social à condição de uma determinada identidade político-cultural não é automática. É no espaço geográfico "que toda acção histórica põe em presença dois estados da história (ou do social): a história no seu estado objectivado, quer dizer, a história que se acumulou ao longo do tempo nas coisas, máquinas, edifícios, monumentos, livros, 
teorias, costumes, direito, etc., e a história no seu estado incorporado, que se tornou habitus ${ }^{4}$.(...) Esta actualização da história é consequiência do habitus, produto de uma aquisição histórica que permite a apropriação do adquirido histórico. A história no sentido de res gestae constitui a história feita coisa a qual é levada, 'atuada', reactivada pela história feita corpo e que não só actua como traz de volta aquilo que a leva ( segundo a dialética do levar e ser levado, bem descrita por Nicolai Hartmann) (Bourdieu, 1989 : 82-3, os grifos são do original).

Essa dialética habitat e habitus ou, se se preferir, história reificada e história incorporada ou, ainda sistema de objetos e sistema de ações5, permite-nos captar a constituição da identidade político-cultural e do ordenamento do espaço geográfico como se pode depreender das lutas intensas para afirmar "o modo de percepção legítima" (Bourdieu) do próprio espaço, isto é, das lutas tensas e intensas pelo poder de nomear, afirmar/reconhecer identidades, atribuir valores/sentidos aos diferentes seres, do espaço e do tempo. Afinal, "a passagem do implícito ao explícito nada tem de automático, podendo a mesma experiência social reconhecer-se em expressões diferentes, e porque, por outro lado, as diferenças objectivas mais acentuadas podem estar dissimuladas por diferenças mais imediatamente visíveis (como as que separam as etnias, por exemplo). Se é verdade que existem na objectividade das configurações perceptivas, Gestalten sociais, e que a proximidade das condições, portanto, das atitudes, tende a retraduzir-se em ligações e em reagrupamentos duradoiros das unidades sociais imediatamente perceptíveis, tais como as regiões ou bairros socialmente distintos (com a segregação espacial), ou dos conjuntos de agentes dotados de propriedades visíveis perfeitamente seme-lhantes, tais como o Stände, também é verdade que só há diferença socialmente conhecida e reconhecida para um sujeito capaz não só de perceber as diferenças, mas também de as reconhecer como significantes, interessantes, quer dizer, para um sujeito dotado da aptidão e da inclinação para fazer as diferenças que são tidas por significativas no universo social considerado.

Assim o mundo social por meio sobretudo das propriedades e das suas distribuições, tem acesso, na própria objectividade, ao estatuto de sistema simbólico que, à maneira de um sistema de fonemas, se organiza segundo a lógica da diferença, do desvio diferencial, constituído assim em distinção significante. O espaço

\footnotetext{
4. "Aquele que tira o chapéu para cumprimentar reactiva, sem saber, um sinal convencional herdado da Idade Média no qual, como relembra Panofsky, os homens de armas costumavam tirar o seu elmo para manifestar as suas intenções pacíficas" citado pelo próprio Pierre Bourdieu.

5. Em livro recente, Milton Santos (SANTOS, 1997), aponta na mesma direção ao abordar o espaço geográfico como um "sistema de objetos" e um "sistema de ações".
} 
social e as diferenças que nele se desenham 'espontaneamente' tendem a funcionar simbolicamente como espaço dos estilos de vida ou como conjunto de Stände, isto é, caracterizados por estilos de vida diferentes' (Bourdieu, 1989 : 143-4)6.

Podemos, pois, afirmar que são nas circunstâncias dos encontros/das relações/das lutas que se desenham concretamente essas diferenças e que toda classe se constitui, se classifica, se diferencia, constrói um Nós em relação a um Eles, a partir de situações ${ }^{7}$ que atualizam múltiplas possibilidades inscritas nos corpos (história incorporada) através do que Pierre Bourdieu chamou habitus.

\section{Os Novos Elos das Escalas/Escadas do Poder}

A construção da identidade seringueira não estava dada a priori: ela foi sendo tecida nos embates concretos que os seringueiros se viram obrigados a travar nas circunstâncias singularíssimas dos anos setenta/oitenta (tempo) nas regiões do vale do rio Acre, ao longo das BRs 364 e 317, no estado do Acre (espaço).

É claro que os seringueiros existiam naquele lugar/naquele momento, tanto no sentido geográfico como social. No entanto, sabemos, a existência de uma determinada condição socio-geográfica seringueira, ou outra qualquer, não implica necessariamente que venha a se constituir numa identidade político-cultural assumida pelos próprios protagonistas como tal. Já vimos em outro contexto ${ }^{8}$ como aqueles que viviam de extrair o látex se identificaram como agricultores, quando da crise do seringal empresa e a queda do preço da borracha impelira-os a diversificar suas atividades produtivas e a buscar outras estratégias de sobrevivência, tanto material como simbólicas, o que ensejou que identificassem a borracha com seu sofrimento e miséria, sobretudo entre os anos 1920 e 1942, e passassem a perceber a agricultura como sua salvação. Naquelas circunstâncias ser agricultor era estar superando o

\footnotetext{
${ }^{6}$. O mesmo pode ser visto com a importância que Thompson (THOMPSON, 1981: 182) empresta à experiência quando nos diz que "os homens e mulheres retornam como sujeitos, dentro deste termo não como sujeitos autônomos, 'indivíduos livres', mas como pessoas que experimentam suas situações e relações produtivas determinadas como necessidades e interesses e como antagonismos, e em seguida 'tratam' essa experiência em sua consciência e sua cultura ( as duas outras expressões excluídas pela prática teórica) das mais complexas maneiras (sim, 'relativamente autônomas') e em seguida ( muitas vezes, mas nem sempre, através das estruturas de classes resultantes) agem por sua vez sobre sua situação determinada)".

7. Situações no sentido de ações situadas.

8 . "Geografando: Nos Varadouros do Mundo - Da territorialidade Seringalista à Territorialidade Seringueira (Do Seringal à Reserva Extrativista)" tese de Doutorado defendida junto ao Programa de Pós-graduacão em Geografia da UFRJ, Rio de Janeiro, 1998.
} 
extrativismo em decadência. Não nos esqueçamos, todavia, que a borracha mobilizara os so-nhos de toda essa/aquela gente e, como um sonho que fôra mais que um sonho, posto que implicara em toda uma prática social que se materializara no seu modo de vida (e, na memória, no melhor de suas vidas) pode, a partir de novas e outras circunstâncias, ser atual, ser atualizada. Espaço e Memória. Habitat e habitus.

Com a desestruturação dos elos que, "por cima", conformavam o pacto territorial regional/nacional ${ }^{9}$ (1942 a 1958/1967), as relações socioespaciais acreanas sofreram uma profunda transformação que, no entanto, não mereceu a devida atenção dos analistas. Talvez tenhamos aqui no Acre a demonstração do paroxismo de uma formação social que se fez/faz sem reconhecer aos "de baixo" o direito à voz, primeira condição para que se seja conhecido/reconhecido enquanto portador de direitos.

Os seringais, de fato, começaram a mudar de donos, expressão que viria a ser muito usada para o período dos anos setenta/oitenta quando os "de fora", sobretudo os "paulistas", começam a adquirir terras no Acre ${ }^{10}$. O que não se via no Acre é que uma mudança de donos já vinha se dando a décadas onde os "de baixo", enquanto ocupantes, mais do que se apossar das condições naturais de produção, estavam se tornando, rigorosamente, trabalhadores livres, seringueiros autônomos. É isso mesmo: desde os anos 20 vinha aumentando significativamente no Acre aquilo que o IBGE, a partir dos anos 40, passa a designar como ocupantes, ou seja, aqueles que comandam um estabelecimento de produção sem que sejam proprietários da terra e sem estar subordinados a ninguém. Em suma, sem Estado (não pagam impostos) e sem Patrão (são autônomos).

A idéia já consagrada de que o Acre era um verdadeiro caos fundiário é, assim, indicativa de quadros de referência socioculturais e espaciais diferenciados e, também, de um processo onde os "de baixo" empreendem uma organização socioespacial prática sem que tivesse correspondência nos estatutos legais.

Viu-se, portanto, que a Territorialidade dos Coronéis de Barranco (1942 a 1958-67) entra em franca desestruturação até porque a dominação/hegemonia que exerciam dependia das articulações políticas com os "de fora", para se reproduzir. 1958 e 1967 são datas de triste memória para os Coronéis de Barranco posto que sinalizam a quebra dos elos, dos degraus que os articulavam às escadas/escalas (èchelles) do poder nacional.

\footnotetext{
9. Refiro-me, aqui, à extinção do monopólio de importação (1958) e de exportação (1967) da borracha pelo Estado atendendo às pressões das grandes empresas transnacionais automobilísticas tanto do setor automobilístico, como de pneumáticos. Assim os elos, as alianças, deixaram de se fazer com o bloco histórico regional amazônico (as Casas Aviadoras e Seringalistas) e sim com os grandes capitais internacionais.

${ }^{10}$. Entenda-se que nesse contexto os "de fora" não são mais os que vieram dos sertões nordestinos, como nos finais do século XIX e início do XX, e são, por isso, agora considerados estranhos no ninho.
} 
Por outro lado crescia a importância daqueles que, pelo menos desde os anos 40 (quando, enquanto registro oficial, apareceram pela primeira vez no Censo, em Xapuri) na prática, garantiam sua própria sobrevivência reproduzindo-se por si próprios de modo autônomo: os Ocupantes. Com suas mulheres e filhos, com sua produção não só voltada para o mercado, até porque tiveram que desenvolver suas estratégias de sobrevivência com a crise do seringal enquanto empresa (1870 a 1912-20), integrados à floresta aprendendo com os índios, com os caboclos, plasmaram uma outra sociedade/geografia acreana.

Assim, no Acre, estivemos diante de uma situação sui generis: os seringalistas não colocaram, de fato, resistência ao novo processo que se abria a partir dos anos setenta. Ao contrário, procuraram se desfazer de suas dívidas junto ao Banco da Amazônia vendendo suas propriedades. $\mathrm{Na}$ verdade, sabemos que, do ponto de vista das classes dominantes regionais acreanas, não se tratou propriamente de uma invasão dos "paulistas". As classes dominantes regionais fragilizadas pela quebra de seus elos com o bloco de poder nacional não lhe restara muitas alternativas além daquela que lhes indicara arrogantemente, em 1974, o Presidente da Associação Nacional de Criadores de Nelore do Brasil, Sr. Mario Junqueira, não sem causar tensões entre seringalistas e fazendeiros.

Nessa transferência de titularidade das propriedades que, como não podia deixar de ser, foi, também, uma mudança da naturalidade desses titulares, agora vindos do Sul, houve, num segundo momento, uma mudança radical nas relações sociais com a natureza: não se tratava mais de um processo de desenvolvimento com a floresta, mas de um processo que era, também, contra a floresta. E por tudo que já agregamos na compreensão desse processo sabemos que o complexo seringal-colocação não era simplesmente um lugar de produção de borracha, que era. Era não só um lugar ocupado, que era; era, também, um lugar habitado, habitat e habitus, e assim um locus de conformação de subjetividades.

...Nós temos que... dizer a eles (os compradores de terra) que isso é nosso, não é o que eles compraram do seringalista. Então, se este seringalista vendeu essa posse para ele, ele vendeu o movimento que ele tinha. Então ele vendeu esse mundo de terra com todos esses posseiros, ele deve ter vendido os posseiros também e nós não aceitamos que nós somos tão bandidos para ser comprados. (...) Prá nós a terra tem valor porque é a nossa vida. Não pode ser vendida, que nós não vendemos a nossa vida'.

(DUARTE, 1987 : 113. O grifo é meu.)

É isso que nos ajuda a entender esse seringueiro que reconhece legitimidade no seringalista para vender o movimento do seringal mas não para vender as suas colocações, as suas posses/os posseiros. Com a tentativa de transformar o habitat, isto é, o seringal em fazenda pecuarista, desfazia-se uma relação socio-espacial 
que, como tal, implicava uma identidade, mesmo que de contrários, entre seringueiros e seringalistas. E, mais, sem que aqueles que se tornam os novos proprietários queiram exercer domínio/hegemonia sobre os que ali habitavam ${ }^{11}$.

Se o seringueiro tornou-se autônomo num processo de fundo em que deixou de pagar renda, como a condição de ocupante no próprio censo reconhece, ele agora se verá tendo que se haver com/contra aquele que vem de fora e lhe quer tomar a terra. No entanto, sabemos, considerar a terra sem a floresta não é só uma questão econômica como se quer fazer crer. É uma das maneiras historicamente produzidas de recortar o real. É, sobretudo, uma determinada maneira de se dar valor às coisas, ao tempo, ao espaço, à natureza. É, assim, toda uma cultura. Há, aqui nesse caso, de modo emblemático, um des-loca-mento das relações socioespaciais de poder. Ele implica todo o espaço e não mais só o seringal, a colocação. E a força que os seringueiros tinham emanava do seu espaço-doméstico-e-de-produção. Enfim, é de uma outra tensão de territorialidades que se trata a partir dos anos setenta ...

Assim, o habitat adquire um significado ímpar para se compreender as relações socioespaciais. Afinal, toda uma organização do espaço havia sido engendrada no Acre sob, com ou, como costumava falar Chico Mendes, e que causava uma certa estranheza, o 'pela floresta', que colocará frente a frente esses diferentes processos de territorialização.

Assim, de fato, a partir de 1970 em diante assistiremos a um processo tenso e intenso de conflitos entre aqueles que dependem da floresta para viver e aqueles que querem desmatar, posto que a floresta não tem nenhum valor de uso para quem quer fazer pasto. Para uns, esses habitantes da floresta, trata-se de manter o habitat, locus do seu habitus. Para outros, os "paulistas", para os "de fora”, tratase de afirmar o progresso nessas terras ainda dominadas pela natureza, conforme reza o imaginário da modernidade. Na prática, os portadores desse imaginário, aqueles que o transportam, são fazendeiros ávidos de adquirir as férteis terras acreanas a baixo preço, até porque tratava-se da fronteira mais externa dos 'anéis de Thünen'. Empate !

Deste modo, emerge um movimento dos seringueiros que emana da compreensão interessada do que é comum, o que implica uma comunidade territorial que vá além do espaço vivido, pressupondo-o; que vá além do lugar/dos lugares, contendoos. É isso que diz a expressão união, tão invocada na conformação de identidades coletivas: o que se une é o igual e esse igual se constitui na percepção interessada do que é igual e do que é diferente. "Eles tem o capital, nóis temos a união", assim

\footnotetext{
11. A começar pelo fato de a pecuária demandar um número pequeno de trabalhadores, exceto no período de formação da fazenda. Embora importante não é esse o aspecto que estou querendo ressaltar aqui.
} 
se expressa um seringueiro. "O sindicato não é o presidente. O que faz a nossa força é a necessidade" diz um outro seringueiro diante da ameaça de morte ao líder de seu sindicato. É rigorosamente, uma fala interessada que, assim, reage à ameaça, ameaçando que a luta vai continuar. O conflito se constitui, assim, como um momento privilegiado dessa conformação de identidades, de configuração de "comunidades de destino". É quando cada um começa a perceber que o seu destino individual está num outro com/contra o qual tem que se ligar/se contrapor.

Nesse trabalho de construção de hegemonia, de construção dessa geografia imaginária os intelectuais têm uma papel fundamental e não sem razão fala-se de "visões de mundo". O teórico comunista italiano Antonio Gramsci captou a importância desses intelectuais, sobretudo daqueles que chamou de intelectuais orgânicos, ou seja, daqueles que expressam vontades coletivas de determinados interesses que podem ser de classe, de grupos religiosos, étnicos, entre outros e, deste modo, constróem hegemonias e contra-hegemonias con-sagrando um determinado estágio da correlação de forças políticas e simbólicas numa geografia imaginária. Esses intelectuais com suas falas autorizadas, conhecidas e reconhecidas, tornam o real mais-real, numa espécie de mais valia simbólica. Eles participam de uma luta tensa e intensa pela afirmação do "modo de percepção legítimo" (Bourdieu).

No caso do Acre vamos encontrar esse intelectual tradicional na pena de um Leandro Tocantins, de um Alberto Zaire, de um Artur César Ferreira Reis, Samuel Benchimol como, também, na de Euclides da Cunha. Neles encontramos o "seringueiro-herói" não reconhecido desde a epopéia do Acre ou como "seringueiro-soldado-da-borracha"; o "seringueiro-vítima" da exploração brutal dos seringalistas e dos Coronéis de Barranco, sempre desaparecendo, sempre em extinção; o "seringueiro-fujão", que escapa do seringal endividado dando prejuízo ao patrão; o "seringueiro-que-rouba-o-patrão" colocando paus e pedras no princípio das pélas; o "seringueiro-preguiçoso" que prefere caçar e pescar a produzir borracha; o "seringueiro-caboclo-traiçoeiro" que pode matar o patrão numa tocaia e, ainda, o "seringueiro-bom-de-leite", aliás, o "verdadeiro-seringueiro", o "seringueiro-que-produz-muito", o "seringueiro-trabalhador" que (se) enche o peito não simplesmente para dizer que é um seringueiro, mas que é " $O$ Seringueiro".

Foi com/contra essa imagem hegemônica, esse verdadeiro senso comum construído, que os seringueiros tiveram que forjar, nas mais diferentes circunstâncias, uma nova identidade político-cultural a partir dos anos setenta ${ }^{12}$. Para nós a nova

12. Aqui é preciso retirar a aura positiva que assume qualquer ente quando lhes atribuímos a qualidade de novo/a. Umberto Eco fala de fundamentalismo como aquela prática discursiva que prescinde de argumentar e, tal como um dogma, afirma a qualidade de algo pela simples afirmação. Assim, podemos falar de um fundamentalismo moderno que empresta qualidade positiva a tudo que é novo e negativa a tudo que é tradicional, sem precisar argumentar porque tudo que é novo é positivo e tudo que é tradicional é negativo. O fascismo foi novo apesar de invocar a tradição. 
identidade político-cultural dos seringueiros e caboclos se colocou como uma possibilidade concreta diante da ameaça à sobrevivência material e simbólica derivada da nova configuração socio-geográfica mundial-nacional e, particularmente, acreana, implicada pela co-presença de novos sujeitos/processos instituintes e, portanto, novos encontros/relações com/contra quem terão que se haver a partir do que, concretamente, tiveram que desenvolver suas novas/outras estratégias de sobrevivência, sempre e ao mesmo tempo, material e simbólicas.

Em diferentes situações os seringueiros/caboclos se verão tendo que manipular, num sentido e direção próprios, diferentes atributos, qualidades e estigmas, afirmando-os ou negando-os. Afinal, o "seringueiro-herói" que conquistou o Acre para o Brasil, que foi "soldado da ('batalha' da) borracha", pode não querer ir para a Bolívia expulso pelos "paulistas". Aqui a história incorporada atua, a história é atualizada, a história é atual pelos atos ensejados nas e pelas circunstâncias pelos seringueiros. Afinal, é ele quem produz a borracha que serve para tudo e, assim, é "O Seringueiro", não porque produz muito para o patrão, mas porque produz muito para a pátria. Ou então, a preguiça é o contraponto do negócio, ou seja, aquilo que é visto como ócio pelos patrões pode ser, para os seringueiros, a afirmação da sua autonomia com a caça e a pesca, ou com o roçado que o liberta do barracão e, assim, de fato, contrário à lógica de quem está preocupado com o negócio, com a borracha-mercadoria, que tem que negar o ócio.

Essa identidade vai sendo forjada, portanto, nas circunstâncias, nas situações, no cotidiano com todas as "suas ambigüidades marcadas pelas oscilações entre fragilidade e força, indeterminação e determinação, indefinição e definição" numa dinâmica "da luta de classes constantemente redefinida e que traz à tona a sua riqueza enquanto movimento que engendra transformações sociais; dinâmica essa cujos aspectos frágeis, indefinidos e indeterminados indicam por vezes campos novos de combate ainda pouco vivenciados pela classe ..." (MARONI, 1982:16).

Essa "experiência obscurecida", "oculta", "não-explícita" foi denominada por Amnéris Maroni (MARONI, 1982) como discurso da ação ${ }^{13}$.

13. "O discurso da ação não verbaliza propostas políticas, no entanto elas existem; não propõe alvos claros contra os quais se desenvolve o combate, porém eles não estão ausentes; não define estratégias explícitas para alcançar o fim desejado, porém, estas se fazem o tempo todo presentes. Por sua dinâmica, se faz presente e ausente, contínuo e descontínuo, definido e indefinido. Em outras palavras, o discurso da ação não oferece visibilidade enquanto tal. Ou seja, é preciso 'querer ver' o discurso da ação; caso contrário ele não se mostra. É preciso buscá-lo lá onde ele se esconde; um pouco para além do social visto de forma institucionalizada; para além dos esquemas teóricos que estabelecem verdades prontas e acabadas; para além dos dogmas políticos que estabelecem trajetórias seguras para a transformação social etc. Para que se mostre, o discurso da ação exige de quem quer vê-lo a compreensão de que o poder permeia o social de múltiplas formas; e também a compreensão de que a luta que tem lugar 'aqui e agora' traz em si propostas de intenções futuras, não asseguradas de antemão pela inevitabilidade histórica, mas possíveis de ser construídas” (MARONI, 1982 : 18). 
Enfim, com a Reserva Extrativista os seringueiros obtiveram uma chancela formal de reconhecimento, de direito, resultante de um longo processo de lutas que conformaram habitus, habitats, modos de vida e de produção. Essa invenção que o movimento dos seringueiros produziu ao ser sancionada oficialmente como uma Unidade de Conservação Ambiental ${ }^{14}$, tende a ser vista como uma entidade jurídica reificada e, tal como o território enquanto limite do poder de Estado, ocultar os, muitas vezes sangrentos, processos (os fronts) e seus sujeitos instituintes.

A Reserva Extrativista expressa a Territorialidade Seringueira com os recursos materiais, políticos e simbólicos que o movimento dos seringueiros dispunha no momento que vai de 1985, quando a idéia é, pela primeira vez formulada como tal, a 1990 quando é con-sagrada e sancionada formalmente, tendo grafado a terra, construído seus varadouros não só com os memoriais com suas descrições e seus mapas necessários para a decretação legal mas, também, deixando rastros de sangue pela floresta.

O que tentaremos agora é expor essa descoberta da pesquisa: a Reserva Extrativista como expressão da Territorialidade Seringueira e, como tal, como materialização de um processo/sujeito instituinte que é o movimento dos seringueiros. Tentar expor como o instituído contém esse processo instituinte, ver no produto os seus produtores, na criação os seus criadores. Acreditamos que, assim, estamos contribuindo não só para explicitar uma temática de importantes conseqüências teórico-conceituais para a geografia como para explicitar que, subjacentes aos territórios (Reservas Extrativistas, por exemplo), existem processos/sujeitos instituintes (movimento dos seringueiros) e, assim, que a Geografia, mais do que um substantivo é, sobretudo, um verbo: é o ato/a ação de marcar, de grafar a terra.

\section{Nova Espacialidade, Novos Meios, Novos Mediadores - algumas reflexões teóricas em diálogo com a empiria}

Quando uma nova geografia social se engendra mudam, como não poderia deixar de ser, as relações dos lugares entre si e dos espaços entre eles e, assim, mudam as hierarquias, as escalas. É a ordem social que muda ${ }^{15}$. Nessa nova geografia que se engendra no Brasil a partir dos anos cinqüenta o próprio sentido da territorialidade brasileira estará se redesenhando, posto que novos sujeitos se insinuam instituindo novas territorialidades. Não só passamos a ter novos meios de transportes, mas também novos portadores que se fazem através dos mediadores,

\footnotetext{
${ }^{14}$. Passível, inclusive, de transferência para outros contextos socio-geográfico-culturais.

15. Não nos esqueçamos que ordenar é colocar as coisas nos seus devidos lugares, em ordem e, assim, há, no mínimo, uma topologia no próprio processo instituinte do social, de cuja materialidade a geografia é formadora dessa sociedade que a forma.
} 
eles mesmos trans-portadores de práticas sociais possíveis pelos novos significados dos lugares nas novas relações societárias que se estão engendrando.

Na medida que a relação personalizada, corpo a corpo, tão característica do meio rural ${ }^{16}$ (o Coronelismo, por exemplo), tende a ser transformada com as novas relações espaciais - migração, rede de transportes e de comunicação - cresce o espaço para os profissionais da intermediação, da mediação - daí dizer-se media -, ou seja, dos profissionais da palavra nos seus mais diferentes modos - a Imprensa, o Direito, a Igreja.

É necessário, portanto, que exploremos aqui um pouco mais essa problemática da língua, ou da palavra se se preferir, enquanto modo de apropriação do mundo, de tornar o mundo um mundo próprio, enfim, de dar sentido ao mundo, ao atribuir sentido aos diversos seres, ao espaço, ao tempo. Não é destituído de sentido que os religiosos atribuam tanta importância à palavra, instrumento, por excelência, da criação/invenção de sentidos. O domínio da palavra é, assim, a possibilidade prática de instaurar a própria socialidade, posto que é o reconhecimento do que se designa como sendo comum que instaura a possibilidade de configuração de uma comunidade de destino, um território, ou seja, que se configure um espaço próprio, quer dizer, com sentido comum ${ }^{17}$.

Além disso a palavra torna o ausente presente, enquanto símbolo que é, e, por isso, tende a substituir aquilo que não é ela própria: o real na sua materialidade. Os meios através dos quais a palavra circula é pleno de significação geográfica. Sociedades que não têm escrita e, portanto palavra escrita, tendem a se organizar até onde se ouve a voz ou até onde o corpo pode se deslocar. A escrita, enquanto técnica, implica um código que tende a emprestar àquele que o domina um poder sagrado de trazer um mundo desconhecido que, mesmo estando em outro lugar, está presente em todos os lugares através daqueles que têm o domínio deste código. Os profissionais da religião sabem, melhor do que ninguém, a importância disso.

O antropólogo e filósofo Pierre Clastres (CLASTRES, 1982) já nos havia alertado para esse caráter da escrita que permite que o poder possa escapar de uma relação espacial imediata, inscrita na relação corpo a corpo, e tornar-se império através da escrita. Assim, não é destituída de sentido geográfico a expressão império e o que aqui estamos tentando exprimir se torna claro quando atentamos para o significado de expressões como 'império da lei' ou o 'império da mídia' ou o 'império da religião': todos eles implicam um poder que vai além do local. $\mathrm{O}$ poder local, como aquele regido por relações coronelísticas, não invoca o 'império

16. Anthony Giddens fala que essa co-presença física é característica de todas as sociedades até o século XIX. O interessante é que este autor destaca exatamente essa dimensão que chamamos de deslocalização como característica da sociedade capitalista industrial moderna (GIDDENS, 1989).

17. Mesmo que regido por relações contraditórias, posto que para haver contradição é necessário que haja identidade. 
da lei'. A lei, por sua vez, dizem-nos, deve ser impessoal, não deve olhar para quem se volta e deve ser igual para todos. Em suma, uma lógica conflitante com a lógica do favor.

Tomando-se como referência aqueles que habitam o mundo rural ${ }^{18}$, essa passagem do lugar para o espaço mais amplo coloca-os, sempre, na contingência de ter que se relacionar com os intermediários em virtude, antes de tudo, da própria dispersão espacial inerente às atividades agrícolas (ABRAMOVAY, 1992). É isso, por exemplo, que leva o extrator seringueiro a reconhecer como legítima a função que o barracão/o patrão cumpre no movimento do seringal, apesar de saber que a escrita ali presente parece, sempre, lhes tirar mais do que devia. Esse sentimento é da mesma natureza daquele que temos em relação àqueles que aumentam os preços ao consumidor e pagam pouco ao produtor. Assim, é nesses intervalos entre os lugares, onde se inscrevem os (inter)mediadores, os que vivem na/da travessia, atravessadores que podem ser tanto aqueles dos negócios da economia, como aqueles dos negócios do campo simbólico, como da política, por exemplo ${ }^{19}$.

É por aí também que se inscrevem esses muito especiais profissionais da intermediação que são os jornalistas e a Imprensa; ou então esses intermediários das almas, profissionais por excelência das ligações, das religações (religare) que são os profissionais das religiões e as Igrejas; ou então esses intermediários da norma comum, os advogados e os juristas, que exatamente por serem do campo das normas que se querem comuns consagram idéias não locais, mas universais: $\mathrm{O}$ Direito.

Enfim, estamos diante de uma nova territorialidade onde novos segmentos, grupos e classes sociais - jornalistas, advogados, religiosos, políticos e intelectuais de um modo geral - se fazem presentes e, com suas práticas, conformam novos pactos, novas identidades de contrários. Vemos, assim, nessa nova configuração que se está desenhando da geografia social brasileira que novos sujeitos e processos instituintes (e suas instituições que geralmente se querem com maiúscula) estão, como sempre, subjacentes à conformação dessa territorialidade.

É necessário distinguir que há aqueles cuja natureza do seu fazer não é falar/dizer ou escrever o que fazem ${ }^{20}$. Há, todavia aqueles cujo fazer é, por natureza, o dizer/falar/escrever: o padre, o advogado, o intelectual - o jornalista, o professor - e o político enquanto aquele que se inscreve como mediador na Pólis hoje, sabemos, o Estado-Nação.

\footnotetext{
18. O mesmo pode ser pensado para a 'aldeia global' que muitos têm visto como global, mas que deve ser vista como aldeia, ou seja, mundo pequeno onde alguns poucos podem controlar o que se passa, ou pelo menos, acreditam nisso.

19. Afinal, há sempre um preço a pagar pela intermediação, seja por um lado ou por outro, podendo, no entanto, ser maior ou menor esse preço dependendo da correlação de forças políticas (e simbólicas) entre os diversos segmentos.

${ }^{20}$. Que sabem, sabem pois, do contrário, não fariam. Há, assim e sempre, um saber inscrito no fazer.
} 
Há, assim, uma tensão entre aqueles que participam das relações de poder inscritas nas próprias relações quotidianas, do espaço vivido, onde desenvolvem múltiplas estratégias de sobrevivência, conformam toda uma cultura, seu habitus, e aqueles que fazem as mediações cujo fazer é, sobretudo, dizer/falar ${ }^{21}$.

Esse mediador, fique bem claro, pode estar bem próximo, bem pode ser um dirigente sindical, até mesmo de origem autêntica. No entanto, enquanto sindicalista é da sua natureza promover a união e, como tal, desenvolver os atributos necessários ao campo: saber interpretar, saber falar, construir um nós e um eles, promover a passagem do eu-individual ao eu-coletivo. Enfim, o seu fazer-saber já é o interpretar, falar e o seu reconhecimento se faz na medida que os representados se reconheçam na sua fala, que se sintam re-presentados, ou seja, presentes enquanto bandeiras, reivindicações, palavras de ordem, aspirações, desejos. Afinal, a palavra torna o ausente presente enquanto símbolo.

Assinalemos, por todas as suas implicações teóricas e políticas, que há um processo de invisibilização que tenta impor silêncio a esses cuja natureza do seu fazer não é o dizer, processo esse que esquece $e^{22}$ essas revoluções moleculares inscritas nas relações de poder quotidianas, invisibilização essa que é produzida não só pelos chamados intelectuais tradicionais ${ }^{23}$.

A construção de uma identidade coletiva é possível não só devido às condições sociais de vida semelhantes mas, também, por serem percebidas como interessantes e, por isso, é uma construção e não uma inevitabilidade histórica ou natural. E, mais, na afirmação dessa identidade coletiva há uma luta intensa por afirmar os "modos de percepção legítima" (Bourdieu), da (di)visão social, da (di)visão do espaço, da (di)visão do tempo, da (di)visão da natureza.

Há aqui, portanto, na construção das identidades coletivas um lugar privilegiado para os intelectuais, com a ressalva de estendermos esse conceito de intelectual,

\footnotetext{
21. Essa tensão contraditória é inerente às relações daqueles que fazem com seu próprio corpo e aqueles que são os mediadores, os intermediários, os profissionais da media, sejam eles do próprio sindicato, ou do partido, ou da comunidade eclesial de base, ou do jornalista, ou do profissional da militância de uma entidade civil sem fins lucrativos. Não há alternativa.

22. Daí dizer-se que não são ouvidos, que querem ter voz, caso contrário, são esquecidos.

23. Como já nos ensinara Pierre Bourdieu, por um desses mecanismos de deslocamento, se oferece sempre a possibilidade de uma aproximação entre os intelectuais e os "de baixo", posto que a superioridade que tem o intelectual no campo simbólico, onde ele estaria "por cima", não corresponde necessariamente a uma superioridade enquanto poder político e econômico, onde ele estaria "por baixo". Assim há sempre a possibilidade que intelectuais estejam próximos dos movimentos sociais, cujas falas contribuem para forjar a identidade do movimento, até porque, por definição, como intelectuais, é da natureza do seu fazer o dizer. Assim, eles vivem das suas formulações, das suas teorias, "da sua capacidade de análise", enfim do seu capital cultural, em grande parte derivado dos seus títulos que tornam suas falas autorizadas, da sua capacidade de antecipar o futuro (as análises de conjuntura têm esse poder mágico). Assim, é possível que visualizemos um discurso sobre a ação e um discurso da ação.
} 
como o faz o comunista italiano Antonio Gramsci, para além daqueles que o sejam por profissão, como os professores, advogados, padres, jornalistas, cientistas de um modo geral, os doutores e, sim, para todos aqueles que contribuem com suas falas para produzirem "visões de mundo", das (di) visões do mundo e, assim, de forjarem identidades como, por exemplo, homens comuns que se tornam expressão de um eu-coletivo e que são reconhecidos por aqueles que nele se reconhecem . Chico Mendes, Raimundo de Barros, Osmarino Amâncio Rodrigues, Júlio Barbosa de Aquino e Marina Silva, todos seringueiros, são, rigorosamente, intelectuais nesse sentido gramsciano.

Essa tensão contraditória é inerente às relações daqueles que fazem com seu próprio corpo e aqueles que são os mediadores, os atravessadores, os profissionais da media, sejam eles do próprio sindicato, ou do partido, ou da comunidade eclesial de base, ou do jornalista, ou do profissional da militância de uma entidade civil sem fins lucrativos. Não há como escapar à natureza dessas relações, mais cedo ou mais tarde mais ou menos tensas, entre representantes e representados, entre o instituído e o processo instituinte ${ }^{24}$. Vejamos o depoimento de um desses intelectuais.

Indagado por Varadouro porque estava indo "quebrar castanha", já que era vereador, e se isso significava um certo desencanto com a política, Chico Mendes, que ali tinha chegado através do movimento sindical, responde:

- Não é bem isso. O problema é que, como político, estava sentindo certa dificuldade de entrar em contato com os trabalhadores, com o Sindicato. Além disso, o estatuto do Sindicato não permite que eu, como político, seja sócio. Pensei, então, que voltando a ser trabalhador, teria toda liberdade de agir. Por achar que a tribuna da Câmara não dá solução para o trabalhador e por achar que o político que realmente se compromete com a luta do trabalhador deve estar ao seu lado, decidi, então, ir quebrar castanha para estar ao lado dos seringueiros.

(...) É, não é fácil, porque como seringueiro, a gente fica isolado, mais preso ao trabalho e não pode se movimentar para acompanhar o trabalho em outros seringais. Por isso, inclusive, estou pensando em adquirir uma colônia, que permitiria maior movimentação.

Vou (continuar trabalhando) sim. Trabalhando a gente fica perto do povo e no momento em que houver qualquer problema, a gente também se apresenta como um trabalhador, com as mãos calejadas

(Varadouro n. 18, mar 1980 : 05).

A dificuldade está claramente posta entre a classe e os seus próprios instrumentos de mediação, isto é, o sindicato ou mesmo o partido político. A dimensão espacial inscrita no fato político salta à vista (se se quer ver): "a gente fica perto", "a gente fica isolado", "não pode se movimentar", "uma colônia que permitiria

24. Como nos ensinara o filósofo holandês Baruch Spinoza são os encontros/as relações que fazem desabrochar as potencialidades. 
maior movimentação". Para que se seja político é preciso se movimentar, mediar, se deslocar, podendo até mesmo implicar que se deixasse de ser seringueiro para ser "colonheiro", como se chama tradicionalmente no Acre aquele que tem um pequeno pedaço de terra para fazer seu roçado. As circunstâncias levariam a que Chico Mendes tivesse que ser seringueiro e dirigente sindical ao mesmo tempo, o que, convenhamos, não foi fácil.

As tensões que aqui se abrem são enormes, até porque os protagonistas diretos, os seringueiros-caboclos, não dominam esses espaços de intermediação com a mesma naturalidade com que o fazem os intelectuais no sentido estrito. É da natureza dos intelectuais falar do geral, do universal, das leis, das normas, dos processos. São eles que ocupam esses espaços.

No entanto, registre-se, há vários movimentos ${ }^{25}$ que abrem mais possibilidades para que os "de baixo" possam vir a ocupar um lugar de destaque tendo que invocar, também, a idéia de um eu-coletivo, contribuindo para construir identidades coletivas e, assim, tornar-se um intelectual orgânico. Há aqui todo um conjunto de atributos que se colocam como necessários para que se ocupe esse campo como, por exemplo, o domínio de recursos da linguagem (a retórica, a oratória, a escrita) tão necessárias para que se manifeste.

No caso daqueles que, pela natureza do seu fazer, não se encontra o falar, o escrever, a sua força está fortemente associada à sua presença física no espaço. É preciso ocupar o espaço, se fazer presente, rigorosamente, perturbar a ordem, posto que é essa ordem que não lhes reconhece, que não lhes vê. Não sem sentido se diz massa, onde o seu poder está na manifestação da quantidade, do volume, da densidade numa verdadeira medição de forças, onde a individualidade fica subsumida nesse coletivo que tenta, exatamente enquanto coletivo, superar a fragilidade que está inscrita no isolamento, na individualidade. Daí as manifestações, as marchas, as passeatas para que se faça notado. Quando se trata de poder as metáforas espaciais (tamanho, volume, posição que é relação entre lugares) são parte da sua linguagem natural (Foucault).

Como esses atos são, por sua própria natureza, temporalmente pontuais (episódicos), entre esses momentos se fazem necessários os intermediários e, novamente, a valorização de quem dispõe de capital cultural acumulado para representar e, assim, falar em nome de quem não está presente enquanto corpo/matéria, mas enquanto idéia/ símbolos: re-presentar. Daí as bandeiras, as palavras de ordem que tentam fixar a presença na memória coletiva procurando afirmar um lugar na geografia real e imaginária.

Afastemos aqui um possível simplismo que poderia se estabelecer quando falamos da tensão entre os seringueiros/caboclos e aqueles que não o são, como sendo entre os que são do Acre e os que não são. Este jogo é habilmente manipulado sobretudo pelos intelectuais tanto os "de dentro" como pelos "de fora", cada

25. Processos instituintes e suas instituições. 
qual lançando mão do prestígio que acreditam ter no mercado político-simbólico, seja exatamente porque se é "de fora", sobretudo quando se é do Sul do país que, na atual correlação de forças políticas e simbólicas, é o centro do poder na atual correlação de forças nessa geografia imaginária; seja porque se é "de dentro" e, por isso, invocam um maior conhecimento de causa, $d a$ causa, posto que estão próximos, argumentos através dos quais procuram tornar suas falas mais autorizadas, seus modos de percepção mais legítimos, cada qual.

Sabemos o quanto isso é forte quando se trata de analisar o Acre onde os "de fora", do Sul, historicamente exerceram o controle político do território e, particularmente, quando o movimento dos seringueiros, sobretudo após os anos setenta, trouxe para si essa histórica acreanidade num momento de absoluta crise de hegemonia dos setores dominantes tradicionais.

Essas identidades e essas oposições entre os "de dentro" e os "de fora" do Acre, sem dúvida, estão presentes. Todavia, é preciso destacar que as tensões e contradições se dão lá mesmo entre "as bases", onde estaria a classe, e a própria direção dos sindicatos e dos partidos políticos (onde os marxistas dizem estar a consciência da classe) que são, também, instituições da ordem das (inter)mediações, que por sua própria natureza operam com um espaço que se faz numa outra escala e, com isso, já estamos indicando uma hierarquia. Há, assim, um "em cima" e um "em baixo" lá mesmo entre os "de baixo", assim como há um "em baixo" entre os "de cima". As lutas de classes são, assim, mais complexas do que quer uma dialética classes dominantes versus classes dominadas.

A construção de uma possível, mas não natural ou inevitável, identidade seringueira pelo movimento dos ocupantes - índios-seringueiros- caboclos - não se fez, portanto, somente com/contra os "de cima", os patrões, os fazendeiros, os latifundiários, os "paulistas" e os seus intelectuais tradicionais mas, também, com/contra a igreja, os sindicatos, os ambientalistas, os partidos políticos e seus intelectuais.

Essa constatação é fundamental para que superemos um novo senso comum que tenta atribuir a projeção e visibilidade política alcançado pelo movimento dos seringueiros e de sua proposta de Reservas Extrativistas seja ao papel da Igreja, seja ao do Sindicato, seja ao dos Partidos Políticos, seja ao Movimentos Ambientalista, seja a um ou outro Intelectual ligado ou não a cada uma dessas instituições.

O movimento dos seringueiros é mais amplo do que esses outros movimentos/processos instituintes/instituições, posto que o/as abarca, mas não se esgota nele/as ${ }^{26}$. O espaço social é multidimensional e essas múltiplas dimensões fazem com que o movimento dos seringueiros seja também-mas-não-só movimento sindical; também-mas-não-só movimento ambientalista; também-mas-não-só movimen-

\footnotetext{
${ }^{26}$. O mesmo pode ser dito de cada um desses movimentos seja o religioso, seja o sindical, seja o partidário, seja o ambientalista que, com toda certeza, no Acre, se relacionam/se encontram todos com o movimento dos seringueiros e que, também, não se esgotam neste
} 
to de classe; também-mas-não-só movimento cultural fazendo-se sempre, de uma maneira singular: seringueiro.

E o fato de ser seringueira essa identidade em construção indica que o habitat e o habitus tiveram um papel relevante na sua conformação identitária, contribuindo para que se classificassem, isto é, se constituíssem enquanto classe desde que vejamos a classe para além do lugar que se ocupa diante dos meios de produção, como nos ensinaram Thompson, Bourdieu, Castoriadis, Leffort, Chauí, Maroni, de Certeau, Lefebvre, Luxemburgo, entre outros.

O movimento dos seringueiros alcançou uma legitimidade que o inscreve num novo mapa de significações que, até aqui, tem feito com que os seringueiros não sejam esquecidos ou abandonados e, assim, sejam parte de uma nova geografia imaginária que, sabemos, está sempre sendo refeita ${ }^{27}$. O que expusemos nos obrigou a sublinhar o até aqui dessa legitimidade do movimento dos seringueiros, posto que o próprio sucesso de suas propostas, tão bem materializado nas Reservas Extrativistas, nos faz esquecer os processos instituintes que estão subjacentes. Insistimos que não há habitat que não comporte habitus, que não há instituído que não tenha processos/sujeitos instituintes portados/incorporados pelos que o habitam. Assim é necessário que se diga que as Reservas Extrativistas, são a expressão de uma identidade possível dos seringueiros, construída enquanto movimento dos seringueiros e seus encontros (Spinoza) do que a Reserva Extrativista é sua expressão teórico-prática num determinado momento de sua história. Assim, falar de seringueiros sem falar do movimento que deu/dá sentido e qualidade a essa identidade é contribuir para, com essa descontextualização, reduzi-lo ao folclore.

Desmontado o lado seringalista da sociedade acreana, os seringueiros começarão a construir uma identidade política própria. Com a retirada dos "de cima" da cena os "de baixo" tiveram que se haver mais uma vez e em outros sentidos por conta própria. De início, sem dúvida, sem mediações e, depois, com/contra as Comunidades Eclesiais de base; com/contra os sindicatos, e com/sem a imprensa alternativa e com/contra alguns intelectuais e, assim como em algum momento os marreteiros, se constituíram em meios, em mediadores importantíssimos para lhes proporcionar a afirmação de suas matrizes de racionalidade, de seus modos de vida, de seu habitat, a floresta.

Daquela histórica tensão de territorialidades que comandou a sociedade/geografia acreana até os anos sessenta entre, de um lado, a Territorialidade dos Coronéis de Barranco que se estruturava por cima e, de outro, a Territorialidade dos Seringueiros Autônomos que se estruturara por baixo, restara aos protagonistas dessa última ter que se reterritorializar numa luta tensa e intensa com/contra os novos protagonistas chegados do Sul, os "paulistas".

27. Essa legitimidade impele todos os outros movimentos a procurarem se qualificar invocando aquelas qualidades que acreditam suas e que vêm traduzidas na identidade seringueira. 
Nossa pesquisa permitiu identificar alguns desses encontros através dos quais os seringueiros construíram sua própria identidade e que estão materializados na Reserva Extrativista, numa evidente Territorialidade Seringueira. Encontros esses cujos sujeitos instituintes se faziam a partir de diferentes lugares e escalas e com/contra os quais os seringueiros moldaram/foram moldados a partir de suas próprias experiências materializadas/incorporadas. Destaquemos, pois, esses encontros/confrontos:

1- Com/contra o Capital na sua forma específica de fazendeiros pecuaristas ou simplesmente de rentistas que, com seus títulos de propriedade, se credenciavam a captar mais valia social via incentivos fiscais, logo, via Estado. $\mathrm{Na}$ linguagem acreana são os "paulistas", os "latifundiários".

2- Com/contra o Estado que ora patrocina o capital, os "paulistas", ora oferece um lote a um seringueiro na própria medida em que a resistência às expulsões aumenta. Os ocupantes seringueiros-caboclos, na medida que se transformam em "posseiros", em Kaxinauá, Apurinãs, em "colonos", em Kampa, em "seringueiros", enfim, na medida que se qualificam exigem que o Estado os qualifique como interlocutores. Assim, ora são tratados como caso de polícia, ora com mini-usinas ou com Projetos de Assentamento Dirigido sempre contra as organizações instituídas pelos próprios protagonistas "de baixo".

3- Com/contra a Igreja com suas Comunidades Eclesiais de Base, suas pastorais, sobretudo a Comissão Pastoral da Terra mas, também, o Conselho Indigenista Missionário - CIMI - e ainda seus párocos mais ou menos ligados e, até mesmo, contra a Teologia da Libertação com/contra sua percepção da questão da terra e da lei. E, sobretudo, com/contra sua visão de colono do sul do país, legalista por sua inserção territorial específica de um Estado dentro de um Estado.

4- Com/contra o movimento sindical, a Confederação Nacional dos Trabalhadores na Agricultura - Contag - e os mais diferentes sindicatos, e toda uma cultura já materializada nesse campo específico, sobretudo a tensão entre o legal, enquanto direito a ser estendido à categoria, e a invenção de direitos. Registre-se que a Reserva Extrativista não é uma figura jurídica dada. É, muito mais, invenção de direitos o que, por si mesmo, indica sua relação com/contra a legalidade.

5- Com/contra o Movimento Ambientalista que via mais a floresta do que os Povos da Floresta e, reconheçamos, menos no Acre do que nas escalas nacional e internacional. Registre-se que a Reserva Extrativista é uma ruptura teórica com o conceito de unidade de conservação ambiental que não incorpora o homem e sua cultura como seu protagonista e aponta para aquilo que Enrique Leff chamou racionalidade ambiental (LEFF, 1994).

6- Com/contra os Partidos Políticos que, assim como expressavam, nas diferentes circunstâncias, as demandas postas pelos seringueiros, ao mesmo tempo que- 
riam tutelá-los. Aqui o PMDB, o PT, o PV, o PC do B e sua dissidência o PRC foram os mais significativos. Aqui, o fato do principal intelectual seringueiro, Chico Mendes, ser ele mesmo comunista jogou um papel relevante nesse jogo de espelhos com/contra o qual o movimento dos seringueiros foi tecendo sua identidade.

7- Com/contra o Movimento Cultural - Varadouro ou pelo Projeto Seringueiro que se encontra com o Projeto Integração do Ministério da Cultura - que busca inventar, nas circunstâncias, uma identidade para um Acre/para uma Amazônia que parecia não ser nosso/a posto que invadido/a por "paulistas" ou pelo "capital estrangeiro". Ser seringueiro e/ou ser caboclo que se faz índio, ou melhor, Caxinauá, Kampa, Jamamadi, Apurinã, Kulina.

Foi sobretudo através do movimento sindical que, no Acre, os seringueiros inventaram sua identidade e a materializaram na proposta de Reserva Extrativista. Através de múltiplos encontros/confrontos os seringueiros vão se fazendo através dessas outras identidades, delas se apropriando/negando e, assim, se definindo, num sentido muito preciso do que seja definir, isto é, que busca se delimitar, num processo de autonomia que, sabemos, mergulha numa trajetória histórica secular.

Esse Seringueiro Autônomo, ocupante, que dominava a paisagem acreana, com seu

discurso da ação não verbaliza propostas políticas, no entanto elas existem; não propõe alvos claros contra os quais se desenvolve o combate, porém eles não estão ausentes; não define estratégias explícitas para alcançar o fim desejado, porém, estas se fazem o tempo todo presentes. Por sua dinâmica, se faz presente e ausente, contínuo e descontínuo, definido e indefinido. Em outras palavras, o discurso da ação não oferece visibilidade enquanto tal.

(MARONI, $1982: 18$ )

Esse Seringueiro Autônomo é que se constituirá no sujeito da resistência, de uma luta para afirmar um determinado modo de ser, de existir.

\section{A TERRITORIALIDADE SERINGUEIRA}

Resumo: O artigo parte do pressuposto que na expressão "luta de classes" o termo forte é "luta" e não "classes", acompanhando o historiador inglês E. Thompson e o sociólogo francês P. Bourdieu. Assim, é a luta que cria o movimento social entre os seringueiros, evidenciando-se que são as lutas, e não o contrário, que dão origem às classes. O movimento social é visto, assim, rigorosamente, como "mudança de lugar" (social). O movimento dos seringueiros significa a passagem da ação territorial à identidade que ela inventa, validando a teoria da ação de que é através das lutas que o implícito cresce e ganha a dimensão do explícito.

Palavras-chave: Teoria da Ação, Luta territorial, Identidade. 


\section{RUBBER-TAPPER'S TERRITORIALITY}

Summary: This article has the pressuposition that in the expression "class struggles" the main term is "struggle" and don't "classes", likewise the English historian E. Thompson and the French sociologist P. Bourdieu. So, the struggle create the social movement among rubber-tappers, showing that the struggles originate classes, not the opposite. The social movement is seen just as "change of (social) place". The rubber-tappers movement means the way from the territorial action to the identity that it creates. So, it validates the action theory in which it is through the struggles that the implicit grows and acquires the concret dimension of the explict.

Keywords: Action Theory, Territorial Struggle, Identity.

\section{BIBLIOGRAFIA}

ABRAMOVAY, Ricardo (1992): Paradigmas do Capitalismo Agrário em Questão, São Paulo Ed. Hucitec.

BOURDIEU, Pierre (1989): O Poder Simbólico, Ed. Difel. Lisboa/Ed. Bertrand Brasil. RJ.

CASTORIADIS, Cornelius (1982): A Instituição Imaginária da Sociedade. Paz e Terra, RJ.

- (1985): A Experiência do Movimento Operário, Brasiliense, São Paulo.

CERTEAU, Michel de (1994): A Invenção do Cotidiano, Vozes, Petrópolis.

CHAUÍ, M. (1982): Cultura e Democracia: O Discurso Competente e Outras Falas. Brasiliense, SP.

CUNHA, Euclydes (1967): À Margem da História, Ed. Lello Brasileiro, São Paulo.

CUNHA, Manuela Carneiro da (1986): Antropologia do Brasil. Brasiliense, São Paulo.

DUARTE, Élio Garcia (1987): Conflitos Pela Terra no Acre: A Resistência dos Seringueiros de Xapuri”, Série Estudos Básicos/UFAC, Rio Branco.

FOUCAULT, Michel (1979): Microfísica do Poder. Ed. Graal. Rio de Janeiro.

GIDDENS, A. (1989): A Constituição da Sociedade, Martins Fontes, São Paulo.

GONÇALVES, Carlos Walter Porto (1989): Os (Des) Caminhos do Meio Ambiente. Contexto, SP.

- (1989): Amazônia: Ecologia, Democracia e Soberania. In Geosul, n. 08, p. 48- 77, Florianópolis.

- (1985): Os Limites d" Os Limites do Crescimento Dissertação de Mestrado. Dept ${ }^{\circ}$ de Geografia UFRJ.

- (1984): Paixão da Terra: Ensaios Críticos de Ecologia e Geografia. Rio de Janeiro, Rocco/Socii.

- (1994): Por Uma Geografia Política da Questão Ambiental. Rio de Janeiro, mimeo.

- (1994): Políticas Públicas Coerentes para a Região Amazônica, GTA/Amigos da Terra. 
(1995): Da Cidade Estado à Cidade Mundo: Alguma Coisa está Fora da Ordem Da Nova Ordem Mundial”. Revista Geosul, Florianópolis.

- (1996): Geografia Política e Desenvolvimento Sustentável in Revista Terra Livre n. 11-12., AGB SP.

- (1998): GEOGRAFANDO: Nos Varadouros do Mundo (Da Territorialidade Seringalista à Territorialidade Seringueira; Do Seringal à Reserva Extrativista). Tese de Doutorado submetida ao programa de Pós Graduação em Geografia da UFRJ.

GRAMSCI, Antonio (1974): A Questão Meridional. Revista TEMAS. São Paulo

GUATTARI, Felix (1983): Micropolítica: Cartografias do Desejo. São Paulo.

- (1987): La Nueva Dimensión del Trabajo. Jornal El País. Madrid. Espanha.

- (1990): As Três Ecologias, Papyrus, Campinas.

LEAL, Vitor Nunes (1975): Coronelismo, Enxada e Voto, Ed. Alfa-Omega, São Paulo.

LEFEBVRE, Henri (1976): Espacio y Política Ed. península, Barcelona.

- (1972): La Vida Cotidiana en el Mundo Moderno, Alianza ed., Madri.

LEFORT, Claude (1982): A Invenção Democrática. Ed. Brasiliense, São Paulo.

LUXEMBURGO, Rosa (1974): Introdução à Economia Política. Ed. Martins Fontes. Rio de Janeiro.

- (1980): O Socialismo e as Igrejas: o comunismo dos primeiros cristãos, Ed, Achiamé, Rio de Janeiro.

MARONI, a (1982): A Estratégia da Recusa: Análise das Greves de Maio de 1978, Brasiliense, SP. II e II.

MORIN, E. (s/d): O Método. Mira-Sintra, Publicações Europa-América, Vols. I,

SADER, M.C. - (1986): - Espaço e Luta no Bico do Papagaio - São Paulo. Tese de Doutorado submetida ao Programa de Pós-graduação em Geografia da Faculdade de Filosofia Ciências e Letras da USP.

SANTOS, Milton - (1994): Técnica, Espaço, Tempo. São Paulo, Hucitec.

- (1996): A Natureza do Espaço: técnica e tempo/ razão e emoção, Hucitec, São Paulo.

SOJA, Edward (1993): Geografias Pós Modernas. Jorge Zahar, Rio de Janeiro

SOUZA, Marcelo José Lopes de (1986): Espaciologia: Uma Objeção. Revista Terra Livre. São Paulo

TOCANTINS, L. (1968): O Rio Comanda a Vida: Uma interpretação da Amazônia, Record ed., R. J.

THOMPSON, E.P.(1981): A Misérisa da teoria ou um Planetário de Erros: Uma Crítica ao Pensamento de Althusser. Zahar. Rio de Janeiro.

Barcelona (1979): Tradicion, Revuelta y Consciencia de Clase, Editorial Crítica, (1987) A Formação da Classe Operária Inglesa: A Força dos Trabalhadores, Crítica, Barcelona. 